\title{
Porphyry Copper Mineral Prospectivity Mapping Using Interval Valued Fuzzy Sets Topsis Method in Central Iran
}

\author{
Ali Reza Jafari Rad ${ }^{1,2 *}$, Wolfgang Busch ${ }^{2}$ \\ ${ }^{1}$ Geomatics Department, Geological Survey of Iran, Tehran, Iran \\ ${ }^{2}$ Institute of Geotechnical Engineering and Mine Surveying, Clausthal University of Technology, \\ Clausthal-Zellerfeld, Germany \\ E-mail: ${ }^{*}$ alirad@yahoo.com,wolfgang.busch@tu-clausthal.de \\ Received July 31, 2011; revised September 2, 2011; accepted September 14, 2011
}

\begin{abstract}
Geospatial Information System (GIS) provide tools to quantitatively analysis and combination of datasets from geological, geophysical, remote sensing and geochemical surveys for decision-making processes. Excellent coverage of well-documented and good quality data enables testing of variable exploration modeling in an efficient way. The study area of this research is the most important part of $\mathrm{Cu}$ (Mo) porphyry - type mineralization belt in Iran. There are some well-known porphyry copper deposits in this region like Sarcheshmeh and Meiduk mines, but certainly there are same grounds to search for new porphyry deposits. The risks of developing mineral resources need to be known as accurately as possible, with regarding to all features those are effective in mineralization. These features can be recognized respect to Critical Genetic Factors (CGF's) using Critical Recognition Criteria (CRC) for each type of mineralization. CGF's can be employed for designing a Conceptual Genetic Model (CGM). Evidence maps create on the basis of CGM and then integrate together for production of Mineral Prospectivity Map (MPM). This map categorizes the areas based on their exploration importance. There are several techniques for creation of MPM. Interval Valued Fuzzy Sets (IVFSs) TOPSIS method was applied in this research. This method as a knowledge-driven method, allocate appropriate weights to layers on the basis of the effective membership, non membership, and non-certainty. The fundamental concept of TOPSIS is that the chosen alternatives should have the shortest distance from the positive ideal points $\left(\mathrm{A}^{*}\right)$ and the farthest distance from negative ideal points $\left(\mathrm{A}^{-}\right)$.
\end{abstract}

Keywords: Mineral Prospectivity Mapping, Porphyry Copper, IVFSs TOPSIS, Iran

\section{Introduction}

Iran like other developing countries relies on the use of their natural resources to support their economic development. It is clear that, oil is the most important natural resources but, utilization of mineral deposits has a long antiquity in Iran. In particular, the exploration of mineral resources has traditionally been a significant component of the Iran economy.

Increasing of the base metal prices like Copper, Iron, Lead and Zinc especially at the recent years causes to attention for finding new resources more and more because one reason for decline in economic development of many countries is decrease of known mineral deposits. In the study area of this research, there are some reports about geology, geophysics, geochemistry, ore deposits... but, many of them were prepared in hard copy format and some others don't have standard database or have disparate datasets, also some datasets are not reliable. Beside that these information haven't considered in regional scale. Therefore development of a geomanagement system using sufficient geosciences data for creation standard datasets that can be useable in GIS environment is vital [1]. Also apply a sufficient integrating method that cover different aspects of MPM is very important [2]. TOPSIS presented by Hwang and Yoon for the first time in 1981 [3]. Malczewski combined GIS and multi-criteria decision making approach [4]. This method is more suitable for raster structure [5,6]. IVFSs TOPSIS method in an intuitionistic fuzzy [7]. Zadeh and et al. recommend fuzzy logic for management of uncertainty [8].

Chen (2000) describes the rating of each alternative and the weight of each criterion by linguistic terms, which can be expressed in triangular fuzzy numbers [9].

Ting-Yu Chen and Chueh-Yung Taso (2007) applied 
the Interval Valued Fuzzy Sets TOPSIS method in decision analysis [10].

\subsection{Study Area, Data Layers and Software}

Iran is located in Alpine-Himalaya orogenic and metallogenetic belt formed after Tethys collision, and therefore has a high potential for different types of minerals [11]. Conventionally a unique Volcano-Plutonic-Arc (VPA) is considered to be formed by subduction of Mesozoic Tethys oceanic crust, but new evidences show that there are different oceanic basins, and associated arcs. One of the most important VPA is Kalkafi Sarcheshmeh-Kharestan (Samani \& Ashtari, 1992) [12], where the study area of this research is a part of this VPA. The study area is located at northwest of Kerman province in central Iran (Figure 1).

The utilized data include digital geology maps, ASTER and LANDSAT ETM imagery, airborne geophysics (magnetics, radiometrics, and electromagnetics), geochemical stream samples and heavy minerals data.

ARCGIS, ENVI and GEOSOFT software were developed for data preparation, analysis and modeling in this research.

\subsection{Geological and Metallogenetic Setting}

The geological formations of the study area consist of ranging from the Cretaceous up to the very recent Quaternary sediments.

The most significant features, related to mineralization, are the sedimentation, magmatic activity and structural displacement that occurred during the Tertiary. The granodiorite and diorite are the most common intrusive rocks. The porphyry copper mineralization is related to regional scale faults (more than $20 \mathrm{~km}$ length) and the most important trends in the study area are N-S, NE-SW, E-W, and NW-SE respectively. At places, where two fault systems intersect, the intrusive bodies are frequently hydrothermally altered [13]. These locations have the best situation for porphyry mineralization. Hydrothermal alteration zoning follows the Lowell and Guilbert pattern [14].

\subsection{Objectives}

The main objectives of this research are as follows:

- To define critical genetic factors, critical recognition criteria and intrinsic parameters for creation of conceptual genetic model for porphyry copper mineralization in the study area.

- To map different types of alteration zones using ASTER and LANDSAT Imagery Data.

- To analysis and interpretation of geophysics and geochemical data, in order to recognition of anomalous region, where related to porphyry copper mineralization.

- To define a method for quantifying spatial associations between known mineral deposits and effective layers in mineralization as input to geologically-constrained predictive mapping of mineral prospectivity.

- To define a favourable geostatistical method(s) for integration the evidence maps, this would be applicable in the comparable areas.

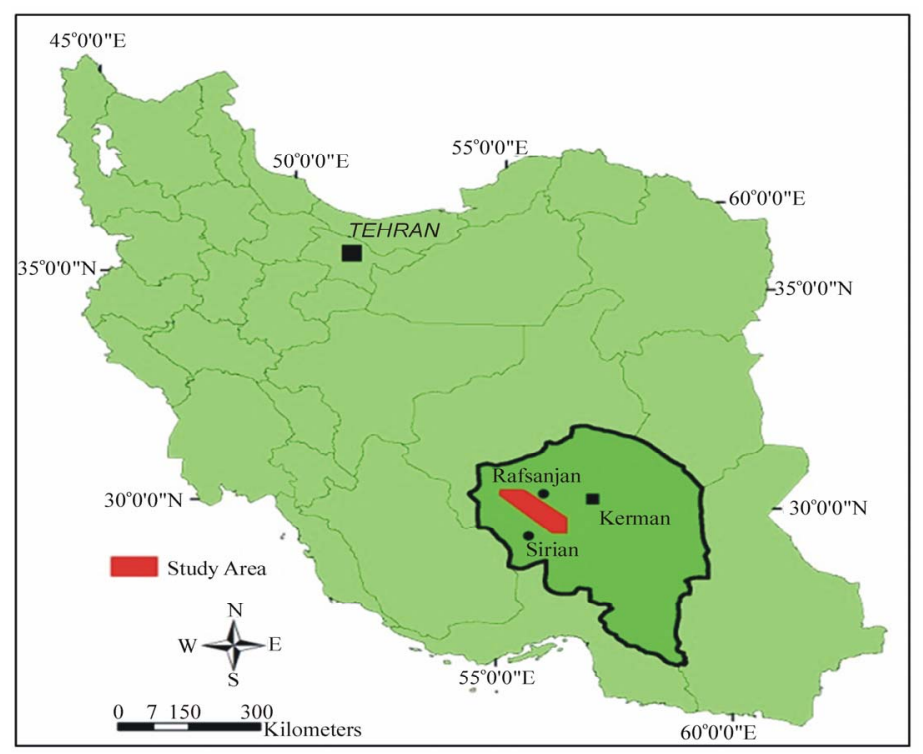

Figure 1. Location of study area in Iran. 


\subsection{Methodology}

This research was implemented as following steps.

\subsubsection{Data Collection and Entry}

Figure 2 has shown how the data turning to a GIS data set.

\subsubsection{Conversion Data to Information}

Based on the model the data convert to information. Figure 3 has shown the steps of information layers preparation.

\subsubsection{Preparation of CGM}

Information layers integration has been carried out using conceptual genetic model. Figure 4 followed the steps of CGM preparation.

\subsubsection{Geospatial Data Processing and Analysis}

Using CGM geospatial information layers are processed

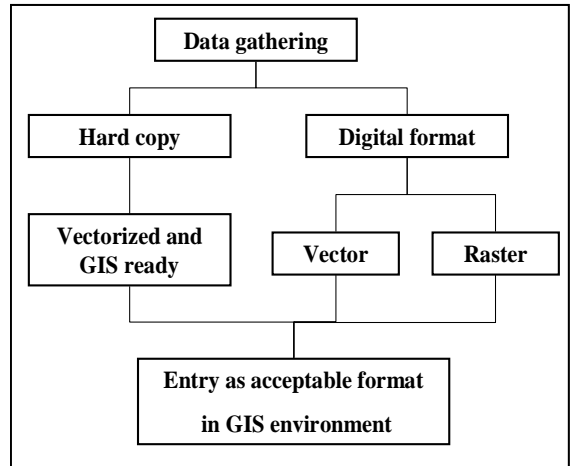

Figure 2. Data entry and Data set preparation.

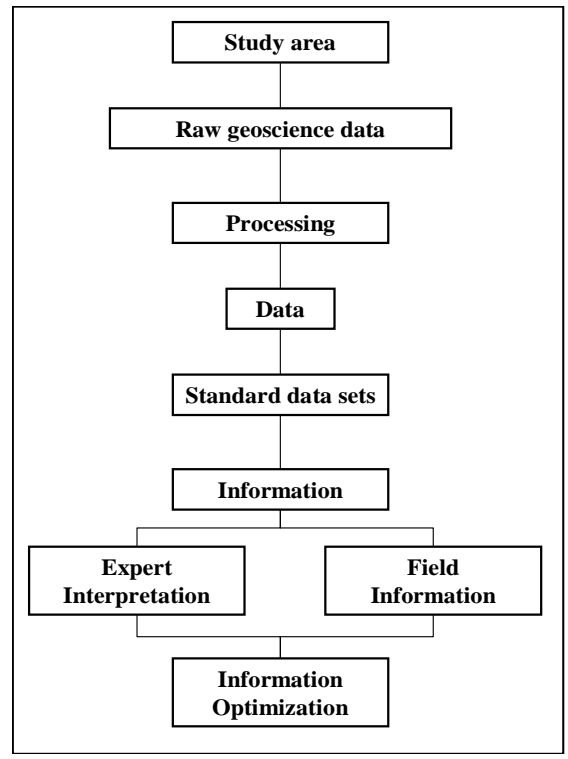

Figure 3. Information layer preparation.



Figure 4. CGM preparation.

and the final weighted layers are prepared (Figure 5).

1.4.5. Preparation of Evidence Maps and Integration Weighted layers analyse for evidence maps preparation. These maps are the final layers and are integrated for Mineral potential mapping (MPM).

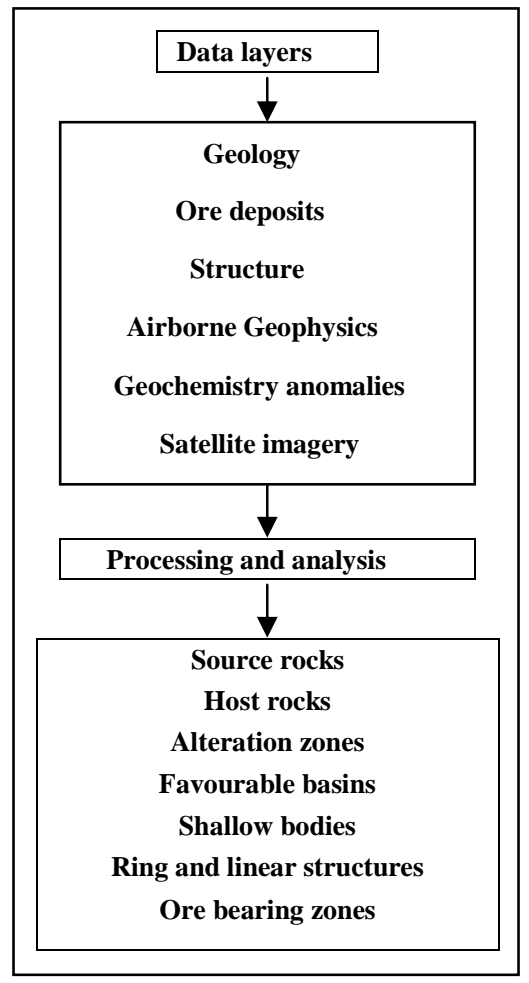

Figure 5. Data processing. 


\section{Data ANALYSIS and Integration}

\subsection{Preparation of Evidence Maps}

According to geological and metallogenetic setting, all features that are important in porphyry copper mineralization were recognized and CGM was presented and the predictor maps were performed. These maps consisting of five thematic layers as follows:

1) Geological thematic layer: the original geology map contained 80 different lithologies. On the basis of the rock types and age, these units were classified to 32 groups and then were reclassified to 6 classes according to their importance in mineralization.

2) Structural thematic layer: the structure features were extracted from: a) geological maps; b) satellite imagery and c) geophysics data. After selecting regional faults and calculating the azimuth, they were divided to different trending and buffered up to 1500 meter. According to buffer distance and trending, they were classified to 7 classes.

3) Alteration thematic layer: as a result of satellite imagery interpretation, phyllic, advance argillic, argillic and propylitic alteration zones were identified and classified according to Lowell and Guilbert model.

4) Geochemistry anomalies thematic layer: several geochemical anomalies were found out during geochemical data analysis and classified on the basis of the zonation of paragenesis elements.

5) Geophysics thematic layer: the results of geophysical data interpretation consist of: intrusive bodies, alteration areas; and lineaments. The anomalies were classified to 4 classes' base on the existence of zonation, and the correlation of anomalies with geological features.

\subsection{IVFSs TOPSIS Method for MPM}

IVFSs TOPSIS method has been specified in support of MPM in this research for the first time. Using this method all significant factors for a knowledge driven modeling system, like allocation Fuzzy Membership (FM), Priority Weights (PW) and predefined targets can be considered.

This technique can be performed in following steps:

1) Classification of each thematic data layers on the basis of the CGM.

2) Allocation of FM to each class of data layers (Table 1 as an example for geology layer).

3) Assign PW to each data layer (Table 2).

4) Multiplication of FM and PW (Table 3).

5) Calculation effective membership (a value), nonmembership (b value) and non-certainty (c value) for each class of data layers (Table 4).
Table 1. FM of geology layer.

\begin{tabular}{ccc}
\hline \multicolumn{3}{c}{ FM_Geology } \\
\hline Class & Fuzzy_1 & Fuzzy_2 \\
1 & 0.7 & 0.9 \\
2 & 0.5 & 0.7 \\
3 & 0.3 & 0.5 \\
4 & 0.2 & 0.25 \\
5 & 0.05 & 0.1 \\
\hline
\end{tabular}

Table 2. PW for geology layer.

\begin{tabular}{cc}
\hline \multicolumn{3}{c}{ W_Geology } \\
\hline W_1 & W_2 \\
0.8 & 0.9 \\
\hline
\end{tabular}

Table 3. Multiplication of FM and PW for geology layer.

\begin{tabular}{cccc}
\hline \multicolumn{3}{c}{ Geology } \\
\hline & $\mathrm{a}$ & $\mathrm{b}$ & $\mathrm{c}$ \\
& 0.56 & 0.19 & 0.25 \\
& 0.4 & 0.37 & 0.23 \\
& 0.24 & 0.55 & 0.21 \\
& 0.16 & 0.775 & 0.065 \\
$\mathrm{~A}^{*}$ & 0.04 & 0.91 & 0.05 \\
$\mathrm{~A}^{-}$ & 0.56 & 0.19 & 0.25 \\
\hline
\end{tabular}

Table 4. “a”, “b” and “c” values for geology layer.

\begin{tabular}{ccc}
\hline \multicolumn{3}{c}{ Geology } \\
\hline class & F1*W1 & F2*W2 \\
1 & 0.56 & 0.81 \\
2 & 0.4 & 0.63 \\
3 & 0.24 & 0.45 \\
4 & 0.16 & 0.225 \\
5 & 0.04 & 0.09 \\
\hline
\end{tabular}

6) Creation several Raster Images (RI) according to “a”, "b” and “c” values for each data layer (Figure 6).

7) Calculation of positive ideal point $\left(A^{*}\right)$ and negative ideal point (A ) for "a", "b" and "c" values in each data layer (Table 4).

8) Measurement distance from $\left(A^{*}\right)$ and $\left(A^{-}\right)$for each layer. For measuring distance in this research, Szmidt and Kacprzyk's [15] equation was specified in the form of Equations 1 and 2.

$S^{*}=1 / 2$ [|(RI of “a value" $\left.-A^{*}\right)+($ RI of "b value” $\left.A^{*}\right)$ - (RI of “c value” $\left.\left.-A^{*}\right) \mid\right]$

$\mathrm{S}^{-}=1 / 2\left[\mid\left(\mathrm{RI}\right.\right.$ of "a value" $\left.-\mathrm{A}^{-}\right)+(\mathrm{RI}$ of "b value" $\left.\mathrm{A}^{-}\right)$- (RI of “c value” - $\left.\left.\mathrm{A}^{-}\right) \mid\right]$

9) Calculation of closeness for preparation MPM using Equation 3:

$$
C_{i}^{*}=\frac{S_{i}^{-}}{S^{*}+S^{-}}
$$






Figure 6. Raster images basis on "a” (green), “b” (blue) and "c" (orange) values.

\section{Results}

Developing mineral resources should start at the pre-discovery stage and continue through feasibility to the development stage. Integrating of predictor maps using GIS allows more probabilistic data analysis techniques and reduces costs and time. On the basis of the IVFSs TOPSIS method, calculation of closeness at the end step of procedure present a MPM that demonstrates the favorable area for pre-discovery exploration (Figure 7).

The original MPM includes different numerical classes. It can be reclassified to descriptive values based on the big jumps in numerical values (Figure 8). First class targets of this research contain 22 regions $(0.76$ percent of study area); include 13 old mining areas and 9 new areas. Setting of all old mining areas inside the first

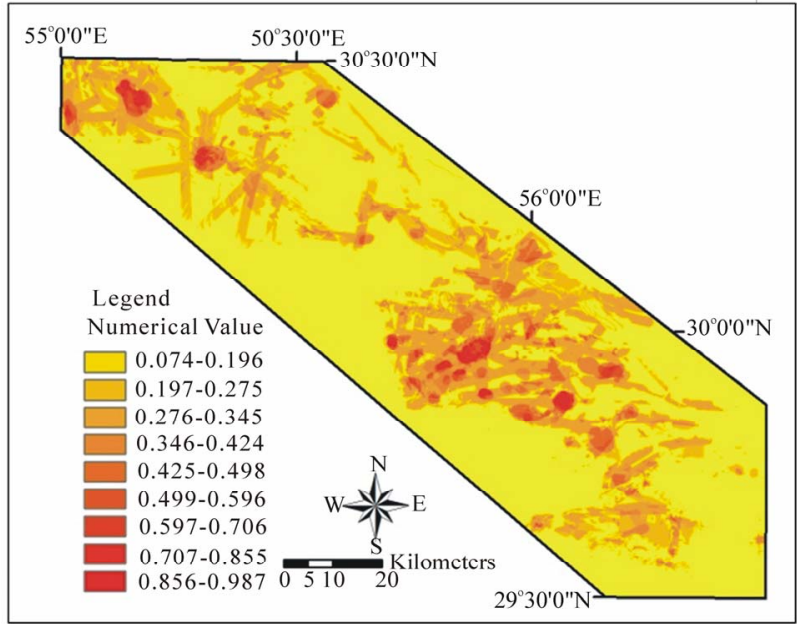

Figure 7. MPM using IVFSs TOPSIS method.

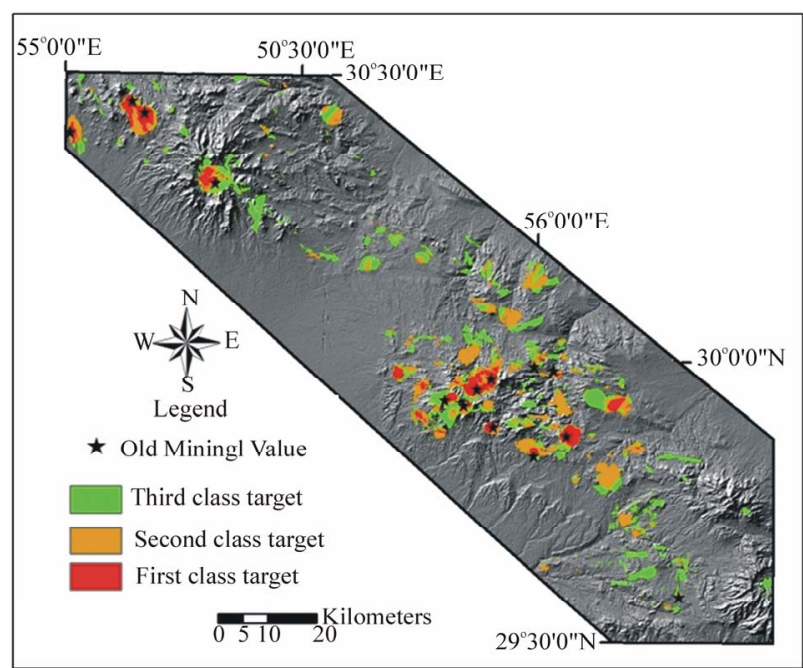

Figure 8. Descriptive priority map. 
class targets, and field observations proves the efficiency of this method. This method can be used in the similar geological and metallogenetic locations in north-westwards and south-eastwards of the study area in Iran.

\section{Conclusions}

Analysis and investigation of first class prospect areas after field checking prove that these areas have characteristics as follows:

- They are located mainly in the intermediate Oligocene_Miocene intrusive bodies, or Eocene volcanicsedimentary complex.

- The porphyry copper mineralization is related to regional scale faults (length more than $10 \mathrm{~km}$ ). The most important trends for mineralization are N-S, NE-SW, E-W, and NW-SE respectively.

- Hydrothermal alteration is extensive and typically zoned on a deposit scale. The main alteration types are:

o Advanced argillic alteration

o Argillic alteration

o Phyllic alteration

- Normally in porphyry copper mineralization, copper and molybdenum geochemical anomalies in center part, and lead, zinc, silver, bismuth, and magnesium geochemical anomalies in outer part of alteration haloes can be detected.

- Airborne geophysics data can be very definitive in locating porphyry copper deposits related to hydrothermal systems. However no unique technique suffices, it is necessary to utilize two or three techniques to maximize the probability of finding new deposits.

\section{References}

[1] F. P. Agterberg, "Estimating the Probability of Occurrence of Mineral Deposits from Multiple Map Patterns,” In: D. F. Merriam and H. Kurzl, Eds., the Use of Microcomputers in Geology, Plenum Press, New York, 1992, pp. 73-92.

[2] R. K. T. Reddy, F. P. Agterberg and G. F. Bonham-Carter, "Application of GIS-Based Logistic Models to BaseMetal Potential Mapping in Snow Lake Area,” Proceedings of Canadian Conference on GIS, Ottawa, 24-26 March 1991, pp. 607-618..

[3] K. Y. Hwang, "Multiple Attribute Decision Making: Methods and Applications,” Springer, Berlin, Heidelberg, New York, 1981.
[4] J. Malczewski, "GIS and Multi-Criteria Decision Analysis,” Wiley, New York, 1999.

[5] J. M. C. Pereira and L. Duckstein, "A Multiple Criteria Decision-Making Approach to GIS-Based Land Suitability Evaluation,” International Journal of Geographical Information Systems, Vol. 7, No. 5, 1993, pp. 407-424. doi:10.1080/02693799308901971

[6] S. S. Katz, "Emulating the Prospector Expert System with a Raster GIS,” Computers and Geosciences, Vol. 17, No. 7, 1991, pp. 1033-1050. doi:10.1016/0098-3004(91)90097-W

[7] K. Atanassov and G. Gargov, "Interval Valued Intuitionistic Fuzzy Sets,” Fuzzy Sets and Systems, Vol. 31, No. 3, 1989, pp. 343-349. doi:10.1016/0165-0114(89)90205-4

[8] L. A. Zadeh and J. Kacprzyk, "Fuzzy Logic for the Management of Uncertainty,” L. A. and J. Kacprzyk, Eds., John Wiley \& Sons, New York, 1992.

[9] C. Chen, "Extensions of the TOPSIS for Group Decision-Making under Fuzzy Environment," Fuzzy Sets and Systems, Vol. 114, No. 1, 2000, pp. 1-9. doi:10.1016/S0165-0114(97)00377-1

[10] T. Y. Chen and C. Y. Tsao, “The Interval-Valued Fuzzy TOPSIS Method and Experimental Analysis,” Fuzzy Sets and Systems, Vol. 159, No. 11, 2007, pp. 1410-1428. doi:10.1016/j.fss.2007.11.004

[11] A. Zarasvandi, S. Liaghat and M. Zentilli, "Porphyry Copper Deposits of the Urumieh-Dokhtar Magmatic Arc, Iran,” In: T. M. Porter, Ed., Super Porphyry Copper \& Gold Deposits: A GlobalPerspeclive, PGC Publishing, Adelaide, 2005, pp. 441-452.

[12] B. Samani and S. Ashtari, "Evaluation of Volcano- Plutonic-Arc in Central Iran, Formed by Subduction of Mesozoic Tethys Oceanic Crust," Geosciences, Geological Survey of Iran, Vol. 1, No. 4, 1992.

[13] S. R. Titley and R. E. Beane, "Porphyry Copper deposits,” In: B. J. Skinner, Ed., Economic Geology Seventyfifth Anniversary Volume 1905-1980, Economic Geology Publishing Co., Littleton, 1981, pp. 214-269.

[14] J. D. Lowell and J. M. Guilbert, "Lateral and Vertical Alteration-Mineralization Zoning in Porphyry Ore Deposits," Economic Geology and the Bulletin of the Society of Economic Geologists, Vol. 65, No. 4, 1970, pp. 373-408. doi:10.2113/gsecongeo.65.4.373

[15] E. Szmidt and J. Kacprzyk, "Distances between Intuitionistic Fuzzy Sets,” Fuzzy Sets and Systems, Vol. 114, No. 3, 2000, pp. 505-518. doi:10.1016/S0165-0114(98)00244-9 